\title{
DA ESTEREOTIPIA
} AO SIGNIFICANTE: MOVIMENTOS A PARTIR DE UM TRATAMENTO EM INSTITUIÇÃO

\author{
Flavia Vasconcellos
}

(1)

recorte clínico exposto a seguir refere-se a uma criança que, durante 4 anos e meio, recebeu tratamento na Pré-Escola Terapêutica Lugar de Vida. O objetivo é poder usá-lo como estímulo à reflexão acerca de alguns conceitos teóricos que a clínica das psicoses e autismo infantis nos impõe. Para um diagnóstico preciso seria imprescindível a contribuição do material relativo à escuta dos pais. No entanto, este trabalho está focado em alguns movimentos, observados nos grupos de atividade, que foram "garimpados" a partir das anotações' e discussões clínicas realizadas em equipe.

André ${ }^{2}$ iniciou seu tratamento no Lugar de Vida aos quatro anos; atualmente, está com oito. Foi sua mãe que o trouxe com a queixa inicial de que seu filho gritava, não falava, era muito nervoso, incomodava-se excessivamente com barulho e não suportava ouvir um "não". Quando bebê, chorava muito e chamava a atenção por ser muito parado, principalmente no olhar. Não se interessava por nada. Muito ligado nele mesmo, ficava por muito tempo entretido com os movimentos das próprias mãos ${ }^{3}$.

Psicanalista, coordenadora do ateliê de música e coordenadora geral de cursos do Lugar de Vida. 
No início de seu tratamento, ficava muito nervoso, gritava e batia em si mesmo com força, ao se deparar com algum limite. Mantinha-se a maior parte do tempo à margem do grupo. Frente a alguma aproximação, fosse de criança ou de adulto, encarregava-se de entrepor novamente uma distância calculada e suportável do outro. Quando, eventualmente, entrava em alguma proposta de jogo, invertia imediatamente a sua regra, o que lhe permitia suportar participar. Apresentava algumas estereotipias: fazia movimentos com suas mãos, que eram acompanhados por uma "sonoplastia". Seus gestos eram entrecortados e repetidos automaticamente.

Durante o tempo de seu tratamento, pudemos observar a permanência de algumas brincadeiras, que foram se enriquecendo ao longo do tempo. André manteve, pelas várias atividades, brincadeiras de cair, desmontar, dar trombada, além de outras.

No grupo educacional, por muito tempo seu interesse esteve circunscrito às garrafas de boliche e ao jogo de letrinhas. André lia e escrevia. Logo que chegava pedia: "Letlinhas". Não aceitava com facilidade fazer outras coisas ${ }^{4}$. Foi necessário fazer um acordo com ele: poderia brincar com as letras nos últimos minutos do grupo. Às vezes aceitava, outras vezes se jogava no chão, gritando e se batendo. Com o boliche, divertia-se derrubando as garrafas. Caía junto, ele mesmo, com uma expressão de prazer. Fazia isto repetida e incansavelmente; foi preciso "negociar" o momento de jogar boliche com o momento de fazer as atividades propostas. Com as "letlinhas", que não eram só letras, mas números também, entretinha-se fazendo contagens progressivas e regressivas, finalizando com o som de uma campainha, que a mãe dizia ser o som do microondas.

No grupo terapêutico, surgiram variáveis das brincadeiras de cair. Andava no parapeito da janela, todo equilibrista, até chegar ao lado dos colchonetes. Despencava deliberadamente gritando "ai", ou dizendo ao se levantar: "caiu".

Trecho reduzido de registro de um grupo terapêutico:

"Chega pedindo para contar histórias. Pega o bebê, finge que lhe dá banho. Alcança o martelo, martela a mesa. Diz que quer desenhar. Não desenha. Pergunta para a terapeuta: 'Quer brigar, quer? Vamos jogar, vamos?' Joga tudo para cima e diz 'caiu, quebrô "Vamos montar, vamos?'. Vai para os colchonetes. Fica pulando, falando: 'fumaça, estolou, palou'. Anda fazendo gestos com as mãos (estereotipia). 'Atenção, ponte do rio que cai'. Cai, fazendo som com a boca que imita bolinhas de ar na água. Termina fazendo a brincadeira do Bom dia, Boa Noite ${ }^{5}$."

Neste fragmento, aparece, de modo enfático, o denominador comum de suas brincadeiras, que parece ser a possibilidade de experimentar a queda em situação lúdica. 
Inventa uma ambulância, que o recolhe, ajuda-o a se levantar e o trata. E, após circular muito essa brincadeira, também pelas outras atividades e começando a incluir outras crianças no jogo, inventa o "Hospital do Câncer". É nesse hospital, que, ao lado da terapeuta, vai poder nomear as partes do corpo que "queblô", e que vão ser consertadas. Pede para a terapeuta consertar o "bilu" (nome para o pênis, que ele diz com entonação de nenê). No mesmo dia, cai e se machuca de fato. Chora muito, mas lembra-se de chamar a ambulância, sugerindo que a construção imaginária feita nas brincadeiras possa lhe ter criado um recurso simbólico contra a angústia da castração.

Recentemente, fizemos mudanças importantes na montagem da instituição, o que significou para cada criança mudanças na formação dos grupos de atividades, no horário do atendimento, na seqüência. Para João, outra criança de seu grupo, a mudança foi vivida como terrorífica. Explodiu em uma crise violenta ao perceber a mudança. Entrou na sala do ateliê de música com muita dificuldade, esparramando-se logo na soleira da porta, onde ficou durante alguns minutos gritando, chorando, "crispando" o corpo sem controle, e absolutamente impedido de escutar a nós, coordenadoras, que tentávamos assegurar para ele que, apesar de algumas coisas estarem diferentes, ele ainda era o João, nós continuávamos lá ... Resgatamos a atividade que vínhamos realizando no ateliê, por sugestão sua: na época trabalhávamos o tema orquestra. Nada parecia ter efeito. As crianças de seu grupo, nesse dia, ficaram muito assustadas. Correram, cada uma para um canto à margem da sala e, mudas, de olhos arregalados, observavam imóveis o desespero do colega. André tem uma idéia. "Montado" em um colchonete, aproxima-se de João, com cautela, fazendo um som de ambulância com sua voz. Ao lado de João, nomeia: "a ambulância". Ainda muito agitado, J. se agarra ao colchonete/ambulância e deita-se sobre ele. Aos poucos, vai resgatando alguns contornos para si, que lhe permitem recuperar a possibilidade de participar, timidamente, da atividade.

É relevante apontar que todas as brincadeiras que fazia eram acompanhadas de uma sonoplastia.Freqüentemente, o som era adequado à situação, outras vezes não tinha uma ligação necessária, embora sugerisse com uma certa precisão do que se tratava.

No ateliê de música, quando é proposta uma atividade com fontes sonoras, André tem uma participação bastante expressiva. Identifica todos os sons, às vezes nomeando a fonte: "som de piano", outras vezes desdobrando-o: "para fazer vitamina" - referindo-se ao liqüidificador - "som de dirigir", referindo-se ao carro.

O som do telefone o faz recordar uma música que havia composto no ano anterior. "Alô, pizza. tãtãtãtãtãtã trimmmmm". A música, grafada em uma folha de papel, é apresentada. Recorda-se, lê tal 
qual uma partitura.

Sua música é uma frase seqüencial de sons. Ele a executa com a voz, o som da cadeira arrastando no chão, dramatizando uma queda do parapeito da janela sobre os colchonetes. Há uma ordem da qual ele não se esquece e cada som tem uma duração e altura diferentes. A grafia representa o som emitido.

Há dois tipos possíveis de grafia, além da notação musical tradicional: a representação através da fonte sonora e a representação que extrapola a relação causal. A segunda forma de grafia exige um conhecimento das leis da linguagem: significado e significante não têm uma relação de contigüidade.

A grafia de sua música se encontra no segundo grupo de notações possíveis. São desenhos cuja relação com o som é arbitrária.

Na música, durante muito tempo, o que mais chamou a atenção de André foi o marcador de tempo que é acionado junto com a fita. Ficava sentado de frente para o som praticamente durante todo o grupo acompanhando os números. Quando a música parava, tirava a fita e controlava o marcador através dos comandos "play", "rew"e "ff". "Quando chega no dez ganha", "Faltam tlinta segundos".

Elaborou-se uma atividade a partir deste impasse: como fazer esta criança se voltar para o grupo. Começamos a trabalhar a música do relógio. A proposta era escrever a letra da música. "Passa tempo tic-tac, tic-tac passa a hora, chega logo tic-tac, tic-tac vai-te embora...". Acompanhamos durante algumas semanas as crianças nessa atividade, não impusemos limite de tempo. Começamos a atividade desenhando o relógio no chão, onde as crianças podiam andar em círculos no lugar dos ponteiros. André corria, de vez em quando, até a lousa onde desenhava o seu relógio, depois voltava para seu posto e continuava a sua incansável tarefa de acompanhar-controlar os números do marcador. Gostava, também, de andar sobre o grande relógio desenhado no chão, mas não se aventurava a ficar pela sala por muito tempo. Retornava rapidamente ao seu lugar. Contribuía na escrita da letra, repetindo o trecho recém-cantado para que o escrevêssemos em um papel Kraft extenso sobre o qual todas as crianças podiam deixar suas marcas.

A seguir, apresentamos às crianças uma nova música: $O$ Carro. Imediatamente, André represen-tou um carro em movimento, com um colchonete entre as pernas, "dirigindo" pela sala. Rapidamente, o espaço foi preenchido por "motoristas" que andavam em círculos. Simularam caronas, o trá-fego, paradas no farol vermelho.

André mostrou-se muito atento à letra. Figurava no cenário construído no ateliê movimentos propostos pela música. Gostava, particularmente, de brincar de bater o carro contra um outro e cair, 
fazendo toda a sonoplastia correspondente ao acidente.

Em um final de atividade, apagamos as luzes e "estacionamos" os carros num canto da sala. Ficamos ali sentados, um ao lado do outro, em silêncio.

André, do outro lado, sentado de frente para o aparelho de som, mexendo nos botões de comando do gravador, volta-se repentinamente para nós, aponta os números e diz enfaticamente: "quilômetros".

André está atualmente muito diferente de quando chegou. Criou recursos para suportar os limites, as diferenças, os obstáculos. É uma criança que propõe atividades, reconhece as ausências em seu grupo, nomeia o que há de novo.

\section{O TEMPO DO TRATA- MENTO NA INFÂNCIA COM PROBLEMAS}

A crise, muito precoce, interrompe a estruturação, seja ela neurótica, perversa ou psicótica. Segundo Calligaris (1989), a criança entra em um "estado crepuscular permanente", que, além de interromper violentamente a estruturação, obstrui ao mesmo tempo o desenvolvimento.

São campos de tempos próprios e distintos um do outro: a estruturação tem um tempo lógico; o desenvolvimento, um tempo cronológico, evolutivo. Entretanto, 
se há alguma perturbação no campo do desenvolvimento, se a criança, por exempto, tem tremores ininterruptos, que lhe provocam muita dificuldade em exercer os movimentos básicos como andar, mamar, brincar, isto impõe questões ao campo do sujeito. Questões relativas à dificuldade da mãe em fazer função materna, ou seja, fazer a antecipação simbólica necessária à constituição subjetiva, na qual oferece à criança pontos em que se apoiar, no sentido de constituir uma imagem corporal. Esta imagem quem lhe dá antecipadamente é a mãe, supondo em seu bebê, um sujeito, interpretando seu grito, ou choro, como demanda de algo. Além disso, a criança terá muito mais obstáculos em elaborar brincadeiras, que, como já nos dizia Freud em "Além do Princípio do Prazer", são especulações, experimentações fundantes da subjetividade. A brincadeira, o jogo infantil, é tanto a forma de elaboração e construção de histórias na infância, como também o palco, onde a criança irá adquirir um instrumental básico corporal.

Por outro lado, supondo problemas no campo do sujeito, como na psicose infantil, encontramos efeitos no campo do desenvolvimento. O tempo da maturação do sistema nervoso central é cronológico, há um prazo no qual determinados instrumentais devem ser adquiridos, caso contrário, há perdas reais. É por isso que, sem tratamento, o destino dessas crianças é a deficiência mental e porque na maioria dos casos se observa uma deficiência secundária. Todavia, apesar dessa interrupção, a cognição não é afetada completamente. A criança mantém preservadas "ilhas de inteligência". Algumas dessas crianças lêem e escrevem, sabem fazer contas, como é o caso de André, mas são "habilidades" cognitivas desconectadas do afeto. São "conhecimentos" que não fazem laço social, não têm a função de comunicar-se ou de responder à demanda de alguém. Lêem simplesmente, sem que isso faça laço com nada.

André exibia, no início de seu tratamento, uma série de estereotipias - movimentos ou falas automáticas e ininterruptas, que têm por característica a não possibilidade de fazer laço social. Não eram movimentos repetidos, mas um único movimento sem pausa, sem ponto final. $\mathrm{Na}$ repetição, já há um tempo a ser considerado que prescinde de uma cadeia, o que faz com que a cada repetição haja uma recriação, que necessariamente será diferente do que veio antes, porque esta condição é inerente ao tempo. $\mathrm{Na}$ estereotipia, há uma eternização do mesmo, não pode mudar porque não existe o antes, não há nada nem antes, nem depois. A criança fica eclipsada em um "instante infinito".

$O$ percurso de seu tratamento sugere que a estereotipia tenha evoluído para o brincar por efeito do olhar de um terceiro, no caso, a instituição. Olhar que coloca o movimento sem sentido em uma rede de significações. 


\section{O JOGO NA INFÂNCIA}

Freud inaugurou o campo de investigação acerca do papel de algumas brincadeiras infantis na constituição subjetiva. Descreveu, em "Além do Princípio do Prazer", um jogo realizado repetidamente por seu neto, em que demonstrou o trabalho psíquico contido no brincar. Interpretou a brincadeira em termos dos movimentos pulsionais que estavam em jogo: o Fort-Da é uma experimentação da descontinuidade (desaparecimento e retorno). A criança transforma a experiência vivida em jogo, invertendo os papéis: põe-se a controlar a ausência-presença do Outro.

Alfredo Jerusalinsky (1993) descreve uma outra série de brincadeiras muito freqüentes na psicose:

"Aquilo que dá sustento à criança para produzir seu sintoma, que é a consistência do significante fundamentado no Nome-do-Pai, lhe falta. $\mathrm{Na}$ falta da consistência deste significante (...) ou a criança fica totalmente tomada do lado do auto-erotismo, ou fica totalmente tomada do lado da alterização absoluta. (...) A situação de queda lhe é inexorável, porque não pode deslizar nem sequer um passo sem encontrar à sua frente um abismo, já que o que a sustenta na borda do abismo é a cadeia significante, e se essa cadeia não tem consistência, ela despenca. É por isso que as crianças brincam de cair (...) precisa- 
mente porque é nessa queda que elas fazem o registro de "o que" as recolhe (...) comprova, nesta brincadeira de cair ou lançar objetos, a consistência da sua corda significante."

Tanto o Fort-da, como as brincadeiras de cair ou de lançar objetos, são “jogos estruturantes". Jerusalinsky (1994) assim os denomina na medida em que são jogos orientados no sentido da constituição do sujeito, que podem promover as articulações necessárias para que ela se organize.

Nesse sentido, o terapeuta ou a "terapêutica" estão orientados no sentido de criar campo e sustentar a brincadeira na relação transferencial.

André "ensaiou" quedas em suas brincadeiras. Caía ele mesmo ou lançava objetos pelo ar, além é claro das brincadeiras de se chocar com um outro e cair como conseqüencia desse "acidente".

As brincadeiras não tinham como direção a elaboração ou solução de um sintoma - embora, como disse Jerusalinsky, muitas vezes estas brincadeiras possam ter este caráter de elaboração -, mas a constituição subjetiva. O trabalho contido nessas brincadeiras foi o de construção e apropriação do Simbólico.

O tratamento, desta forma, é um campo que se estabelece no sentido de promover marcas, fazer inscrições, convocar um sujeito.

\section{DA ESTEREOTIPIA AO SIGNIFICANTE}

Se na infância a estruturação ainda não atravessou todos os seus tempos, a intervenção terapêutica pode colaborar para que a criança possa fazer uma travessia, na qual adquira consistência imaginária que contribua para a sustentação de uma inscrição no Simbólico.

Segundo Jerusalinsky (1993), psicose e autismo são estruturas diferentes. $\mathrm{Na}$ psicose, há Nome-do-Pai, mas ele não pode exercer sua função. No autismo, a ausência de inscrição faz com que a criança se posicione com relação à demanda do Outro, como uma demanda de exclusão.

“... se a mãe da criança psicótica a retém junto a seu corpo como representante real de seu falo simbólico (...) a mãe do autista coloca seu filho exatamente na mesma posição que o turista coloca o monumento na fotografia. A mãe do autista é uma turista do desejo. O objeto de seu desejo está fora de seu olhar. A mãe do psicótico é uma profissional do desejo, nada de seu filho escapa a seu olhar."

O autista recebe qualquer demanda como demanda de exclusão. A estereotipia é a forma que ele encontra para responder a 
essa demanda: com algo que não faz nenhum outro sentido além de reafirmar incessantemente a sua ausentificação. A estereotipia não se dirige a nada, perpetua - "la indiferencia y la inercia propria a la cosa". (Levin, 1991) Para Levin, o tratamento dessas crianças deve partir justamente das estereotipias.

Considerando sua relação com os números, neste caso, como estereotipia, o percurso de André sugere que ao mesmo tempo que esta impõe um obstáculo importante ao tratamento, é através dela que se pode conseguir um "alargamento" do próprio ato estereotipado, por onde o terapeuta tenha a oportunidade de se fazer presente para a criança. No autismo, a forma de se fazer presente é justamente na posição de não demandar nada.

"El cuerpo en el autismo permanece mudo, silencioso, carente de toda gestualidad, se mantiene encapsulado y cosificado en esa única posición de mutismo. (...) Posición mortifera donde ningún significante remite a otro, ni lo ordena en el lenguaje. Tanto el cuerpo como las posturas, el tono muscular, los movimientos, el silencio, el espacio y el tiempo, están en una relación de exclusión al lenguaje. (...) De este modo el cuerpo del niño autista se mueve en un tiempo eterno, infinito, sin pausa. En un espacio sin límites, sin un lugar donde poder orientarse, navegando en el vacío propio de la cosa inerte." (Levin, 1991)

A criança autista não pode se mover nem por um milímetro, não porque possa cair num abismo, 
como no caso da criança psicótica, mas por não haver espaço, nem tempo por onde transitar. $\mathrm{Na}$ medida em que a criança adquire algum nível de inscrição subjetiva, isto a coloca numa posição de extremo risco, de incessante ameaça, já que terá, num tempo tardio, de constituir uma cordagem significante minimamente consistente, que lhe permita traçar a distância necessária à sua constituição entre seu corpo e o corpo de sua mãe.

À diferença do autista, a criança psicótica pode fazer laços com o social, e é na exata medida em que amplia esses laços, que irá promover uma maior consistência à cadeia significante. As brincadeiras de cair são, portanto, por um lado experimentações acerca da "resistência" desta corda, por outro, ensaios de enlaces, tentativas de entrada no campo do Simbólico.

\section{CONCLUSÃO}

As brincadeiras que André pôde construir durante seu tratamento, promoveram uma transformação no próprio ato estereotipado. De fato, desse pequeno núcleo puderam derivar significações outras, que vieram enriquecer, dar consistência à cadeia significante. Continuamos nos perguntando a respeito da permanência de algumas "ilhas de estereotipia", que se mantiveram, apesar de todas essas conquistas.

Há poucas semanas no ateliê de música:

- "O que vamos fazer hoje no ateliê de música?" melodia.

- "Ouvir música do relógio!"- responde André, fazendo da frase uma

Entrego-lhe a fita $K 7$, em que estava a música que havia escolhido. Imediatamente, ele a coloca no gravador e faz com que retorne ao início. Zera o marcador e, em seguida, adianta a fita até dizer: "Plonto!" Aperta - "Play" e a música do relógio preenche a sala de atendimento.

Esta cena surpreende pela precisão com a qual André encontrou a música "O Relógio", que já não usávamos há muitos meses nessa atividade. Talvez esperássemos que este saber a respeito dos números pudesse ter sido esquecido ${ }^{6} \mathrm{com}$ a ampliação e modificação do ato estereotipado. De qualquer forma, o investimento dos números do marcador do apareho de som, que durante tanto tempo o entreteve, retornou, agora, claramente contextualizado e referido a partir da assunção de um querer. Posicionou-se frente à pergunta proferida a respeito do que tinham vontade de fazer no ateliê escolhendo uma música e encarregando-se de, ele mesmo, fazer o necessário para que 
sua vontade fosse satisfeita.

André conta, hoje, com recursos simbólicos, tais como a possibilidade de construir uma história, elaborar personagens, cantar uma música, respeitando seu ritmo e sua melodia. Além disso, inventa atividades, incluindo as crianças de seu grupo, reconhece as ausências e "inventa" maneiras de suportar os limites impostos pela cultura. Não apresenta mais crises frente a uma negativa ou a um obstáculo, adquiriu a capacidade de criar novas possibilidades, além do prazer de que hoje pode desfrutar nas atividades que realiza.

\section{REFERÊNCIAS BIBLIOGRÁFICAS}

CALLIGARIS, C. Introdução a uma clínica diferencial das psicoses. Porto Alegre, Artes Médicas, 1989.

- FREUD, S. Além do princípio do prazer. In: Edição standard brasileira das obras completas de Sigmund Freud. Rio de Janeiro, Imago, 1976, v.18.

JERUSALINSKY, A. La educación es terapéutica? Acerca de tres juegos constituyentes del sujeto. Escritos de la Infancia. Buenos Aires, FEPI, v.3, n.4, nov. 1994.

- JeRUSAlinsky, A. Psicose e Autismo na Infäncia: uma questão de linguagem. Boletim da Associação Psicanalítica de Porto Alegre, v.4, n.9, nov. 1993.

LEVIN, E. La clínica psicomotriz - el cuerpo en el lenguaje. Buenos Aires, Nueva Visión, 1991. 


\section{NOTAS}

1 Trabalho escrito comcomitantemente à realização das atividades.

${ }^{2} \mathrm{O}$ nome da criança foi alterado.

${ }^{3}$ Essas informações foram colhidas pela referência do caso, que é o profissional que se ocupa de escutar os pais.

+ No grupo Educacional, a demanda é dirigida à aprendizagem e o enquadre é inspirado na instituição escolar, tendo tarefas a serem realizadas.

"A brincadeira do "Bom dia, Boa noite" ocorria em praticamente todos os grupos terapêuticos, aparecendo esporadicamente nos ateliês. Consistia em acender e apagar a luz dizendo "bom dia", quando a luz estava acesa, e "boa noite" com a luz apagada.

" $\mathrm{O}$ esquecido, neste contexto, faz referência ao recalque, que sabemos ser um mecanismo de defesa próprio à neurose. Também sabe-

mos, entretanto, que $\circ$ tratamento de psicóticos pode promover recalques parciais. 